\title{
GÉNERO Y PROCESOS INTERLEGALES
}

Reseña al libro de Victoria Chenaut, Género y procesos interlegales, México, CIESAS -El

Colegio de Michoacán, 2014

GENDER AND INTERLEGAL PROCESSES:

a review of Victoria Chenaut's book, Gender and inter-process, Mexico, CIESAS The Colegio of Michoacán, 2014

María Teresa Sierra

Doctora

Profesora - Investigadora del CIESAS

Mexico

mtsierrac@hotmail.com

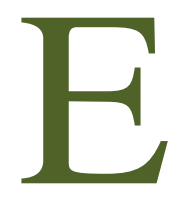

1 libro "Género y procesos interlegales" recoge una trayectoria de investigación de más de 25 años realizada por Victoria Chenaut en la que confluyen dos grandes pasiones: su pasión por los totonacos - un pueblo indígena mesoamericano que habita principalmente al norte del estado de Veracruz y al norte del estado de Puebla, en México- , su cultura, su historia y sus dinámicas de vida; y su pasión por la antropología jurídica como una vía para comprender los sentidos culturales y de poder vinculados al derecho, las dinámicas del cambio social y muy especialmente la dimensión humana de los conflictos sociales.

Este libro es un referente para ambos campos de estudio. Victoria se inspira en el filo antropológico y etno-histórico de los trabajos clásicos de antropólogos como Alain Ichon (La religión de los totonaca, INI, 1973) en su búsqueda por comprender la cosmovisión totonaca, su conexión con el derecho indígena y los ordenamientos jurídicos interlegales. Toca aquí uno de los campos de investigación más fascinantes para la antropología jurídica, referidos a las lógicas culturales como estructuradoras del derecho, pero también más difíciles de abordar. 
Pero principalmente el libro es una contribución a los estudios de la antropología jurídica mexicana y latinoamericana, en una trayectoria que inició hace ya 27 años cuando se publicó el Libro Entre la Ley y la Costumbre. El derecho consuetudinario en América Latina (1990), coordinado por Rodolfo Stavenhagen y Diego Iturralde. Dicho proyecto nos impulsó a varias de nosotras a iniciar un camino de investigación que hasta fechas actuales nos sigue ocupando para comprender la vigencia del derecho indígena y sus formas de relación con el derecho estatal. En este contexto se sitúa una corriente de investigación a nivel latinoamericano que ha nutrido importantes discusiones y redes, como lo es la Red Latinoamericana de Antropología Jurídica (RELAJU), a la cual Victoria Chenaut ha contribuido de manera significativa desde su fundación. Este libro es una contribución a estos debates y es también producto de ellos.

El libro aborda los procesos de relación, cambio y tensión entre la ley y la costumbre, que se expresan en las disputas en las que se ven involucrados indígenas totonacas cuando se enfrentan a la justicia. Esta intensa interacción entre sistemas jurídicos imbricados en una intensa y conflictiva relación, revela la vigencia de procesos interlegales desde los cuales se gesta la normatividad totonaca sin por ello perder su marcaje cultural: son finalmente los actores, que su búsqueda de justicia apelan a ordenes jurídicos diferenciados desde contextos sociales y culturales particulares. El foco analítico de la investigación está puesto en las prácticas jurídicas, en la manera en que los indígenas totonacas usan el derecho para resolver sus controversias y al hacerlo activan el orden jurídico estatal y sus propios marcos normativos. Victoria Chenaut desarrolló su investigación en el municipio de Coyutla, municipio situado en la Sierra de Papantla, en el estado de Veracruz; es en este espacio donde analiza las dinámicas del campo jurídico, como espacio de relación de actores sociales, hegemonizado por el derecho estatal.

II

El libro tiene la virtud de articular una perspectiva histórica de larga duración de los totonaca en la Sierra de Papantla, abarcando un periodo de más de 100 años, con una fina etnografía de procesos jurídicos contemporáneos en la misma región de estudio. Este es uno de los principales aportes y rasgos distintivos del libro de Victoria Chenaut. No solamente remite a la historia para ilustrar el presente, sino que analiza los procesos de formación del Estado en la región del totonacapan y 
destaca de manera especial el sentido en que los totonacos de fines del XIX y principios del XX usaron el derecho para disputar sus tierras, para defenderse del acoso de hacendados y funcionarios, y mas tarde de las compañías petroleras extranjeras interesadas en la explotación de los recursos naturales. De manera muy afortunada Victoria Chenaut no sólo consigue mostrar que los campesinos totonacos han estado vinculados a las dinámicas económicas y políticas regionales y nacionales a lo largo de la historia sino que también han buscado defender sus territorios y formas de vida. Para el desarrollo del capítulo segundo la autora recurre a una sistemática revisión de archivos agrarios, documentos históricos e historia oral que ofrecen un material muy valioso para comprender las dinámicas de cambio poniendo siempre en el centro a los actores sociales. Estos mismos totonacos, o mas bien sus descendientes, situados en el municipio serrano de Coyutla en Veracruz, a fines del siglo XX y principios del siglo XXI, son los principales referentes de la investigación y de la etnografía realizada por Victoria Chenaut en los espacios judiciales del municipio de Coyutla y del distrito judicial de Papantla, recogidos en este libro.

La cosmovisión totonaca y su incidencia en la regulación social. En el capítulo tercero, Victoria sitúa el contexto histórico y cultural del municipio de Coyutla, y su cabecera, bajo el mismo nombre, una región interétnica localizada en la bajada de la Sierra madre oriental, hacia la costa, al norte de Veracruz, estructurada a partir de relaciones coloniales, con un mayoría de población indígena habitando tanto en la cabecera del municipio, como en las comunidades cercanas a la cabecera municipal. Asimismo una minoría mestiza que migró al municipio desde mediados del siglo XIX ocupa el poder económico y político lo que corresponde a un trazo muy similar a otros municipios con población indígena de la Sierra Madre Oriental. No me detengo en las dinámicas del poder caciquil y sus alianzas basadas en el control de tierras y la administración de la población; lo cual aborda con detalle Victoria Chenaut en su libro. Sí destaco el fino análisis de Victoria sobre la cosmovisión totonaca y como ésta permea el ciclo ritual y festivo de las comunidades lo que le permite develar el sustrato cultural que marca las relaciones interétnicas, así como los órdenes de género que lo estructuran. Sin duda se encuentra aquí uno de los aportes centrales del libro de Victoria fundamentales para comprender las normas totonacas. De manera convincente Victoria analiza las continuidades y cambios de prácticas rituales y festivas como es el caso de las danzas, las fiestas y las promesas cuyo 
incumplimiento produce castigos sobrenaturales que podían ocasionar enfermedades y muertes; se trata efectivamente de creencias arraigadas que remiten a la cosmovisión totonaca y rigen en buena medida la conducta social. Pero muy especialmente, Victoria nos introduce en las lógicas culturales vinculadas a las costumbres matrimoniales - como es el caso de la danza del guajolote ebrio para probar la virginidad. Destaca también el sentido en que los modelos de organización totonaca, o su reinvención, permean una organización política paralela en la ciudad de Coyutla, impulsada por los fiscales - cargos religiosos ocupados por los indígenas-, sin ser parte de las instituciones oficiales pero con efectos importantes para la regulación social.

Destaco a continuación lo que considero los aportes principales de Victoria Chenaut al campo de la antropología jurídica desde la experiencia totonaca: el análisis del campo jurídico y la perspectiva de género en los procesos interlegales.

\section{1. ¿ Cuáles son los usos del derecho} que hacen los totonacas de Coyutla? ¿ Qué revelan de la manera en que se construye el derecho en regiones indígenas?.
Un hecho distintivo del campo jurídico en el municipio de Coyutla, es que las comunidades indígenas, o rancherías, parecen no contar con autoridades institucionales fortalecidas donde se ejerza justicia, como si sucede en comunidades indígenas en regiones cercanas que cuentan con juzgados de auxiliares, como es el caso de las comunidades nahuas del municipios indígenas en la Sierra norte de Puebla. Por lo mismo un gran número de asuntos $\mathrm{y}$ disputas que no se resuelven en los espacios informales de las comunidades, suelen llegar a las instancias municipales, el juzgado de paz y la agencia del ministerio público, como instancias oficiales del campo judicial municipal. Es en estas instancias donde cobran vida una serie de negociaciones y procedimientos judiciales que se activan en la medida que los actores sociales acuden a ellas para plantear sus reclamos. El municipio se convierte así en un engranaje institucional entre el Estado y las comunidades.

Victoria Chenaut toma en serio uno de los postulados centrales de la antropología jurídica planteados por Laura Nader referido a que el derecho se hace en las prácticas. Es a partir de litigios y disputas que los usuarios dan contenido a las nociones abstractas del derecho en el marco de los contextos sociales y culturales en que transcurren sus vidas. Tal postulado resulta 
muy sugerente para caracterizar el funcionamiento de las instancias judiciales del municipio de Coyutla, como primer nivel del campo judicial, a través del cual el Estado impone su hegemonía. El estudio fino de los espacios de justicia y los procesos judiciales que realiza Victoria revelan principalmente como el derecho moldea las prácticas jurídicas y a su vez es moldeado por las dinámicas de los procesos interlegales cultural y socialmente situados.

La particularidad del espacio judicial en Coyutla, esta marcada por la cercanía entre funcionarios judiciales y usuarios del derecho y así como una profesionalización del campo jurídico- lo que hace que quienes asumen el cargo de juez o de ministerio público sean abogados. Es justamente en el seguimiento de casos de disputa que llegan hasta a las instancias municipales, el juzgado municipal y la agencia del ministerio público, que Victoria reconstruye las trayectorias de los conflictos, los patrones de uso del juzgado así como el tipo de resolución que involucra a cada instancia dependiendo de los casos y su gravedad: ya sean asuntos que terminan en el juzgado municipal, donde suelen prevalecer las conciliaciones y acuerdos, y los casos penales que siguen un proceso más formalizado y se insertan en la cadena judicial.
En su análisis Victoria Chenaut destaca distintos patrones de uso del juzgado en Coyutla que son muy sugerentes para mostrar la dimensión práctica de las disputas y su resolución así como una serie de condicionamientos sociales, culturales y contextuales que inciden en ellos. Son varios los patrones que identifica, aquí me interesa destacar el hecho que en las distintas diligencias se revela el conflicto cultural que caracteriza la interacción judicial en la que suelen participar indígenas de las comunidades como principales usuarios de los juzgados frente a las autoridades judiciales generalmente mestizas: esto se revela en la falta del domino del español, el desconocimiento de los procedimientos y las leyes, la falta de documentos, etc. Es decir, acuden a la justicia estatal bajo condiciones estructurales de desventaja que obstaculizan que el proceso judicial se ponga en marcha, ya que algunos no conocen su edad, no cuentan actas ni papeles que lo certifiquen, entre muchas otras cosas, lo que afecta el seguimiento del proceso. Dicha situación sin embargo no les impide ser atendidos por los funcionarios judiciales y poner en marcha las dinámicas jurídicas. Es por ello también que Victoria concluye que el derecho es flexible: es decir, al tener que ajustarse a las situaciones y condiciones de los actores derecho moldea y es moldeado 
por el contexto social y cultural en que las prácticas jurídicas tienen lugar.

De esta manera a través del análisis de un conjunto de disputas y litigios Victoria Chenaut muestra las dinámicas productivas del derecho y la apropiación que hacen los actores sociales para su propios fines. Revela así un caleidoscopio de conflictos y un entramado de relaciones sociales, en donde el recurso a la ley se asocia a fines diferenciados como el hecho mismo de destrabar una disputa, presionar un acuerdo, y poner alto a ciertas violencias. Una cantidad importante de los asuntos involucran disputas familiares y remiten muchas veces a cuestiones de herencia, a incumplimiento de obligaciones, y a difamaciones. Lo interesante es que los propios agentes judiciales entran en la negociación y aceptan acuerdos basados en costumbres incluso si estas van en contra de la ley; lo cual viene a ratificar procesos similares de acceso a la justicia en otras regiones indígenas, como es el caso de la Sierra Norte de Puebla, según constatamos en una investigación anterior ${ }^{1}$. Llama la atención así que un nivel de profesionalización del campo judicial no impide que el derecho sea moldeado por los actores y los conflictos y no simplemente se imponga tal cual lo dice la ley. Estos espacios revelan las formas que asumen los procesos interlegales al poner en relación las instancias y normas del derecho estatal ( campo jurídico) con normas provenientes de otras matrices culturales y de regulación.

\section{2. ¿Cuál es la relación entre género y derecho?. ¿De qué manera el} derecho construye al género y a su vez las ideologías de género inciden en el derecho?

La relación entre género y derecho es otro de los ejes que atraviesa el libro y en esto hay un eco con estudios sobre el tema en otras regiones del país. Como bien muestra el libro, el papel del derecho como organizador de los de roles de género y las dinámicas de cambio social puede verse tanto en el campo del derecho indígena totonaca, como en el derecho del estado. En el campo del derecho indígena, en la cosmovisión totonaca, es clara la fuerza histórica de órdenes patriarcales que han situado a la mujer en desventaja frente a los hombres, como puede verse en el campo de las costumbres matrimoniales - pedida de la novia-, y en normas de acceso a la tierra y de la herencia. Dichas normas que involucran conceptos arraigados del honor $\mathrm{y}$ del deber ser, son parte de procesos

\footnotetext{
${ }^{1}$ Sierra, María Teresa (ed) Haciendo justicia. Interlegalidad, derecho y género en regiones indígenas, CIESAS- Porrúa editores.
} 
coloniales que se han ido transformando en consonancia con las dinámicas de cambio social y legal. Lo interesante es mostrar que detrás de los conflictos que llegan al municipio se revelan los ordenamientos de género y los sentidos en que entran en tensión con la legislación del Estado.

Sí bien en el campo del derecho estatal han habido importantes cambios a favor de los derechos de género, no necesariamente dichos marcos legales coinciden con las ideologías de género de los funcionarios judiciales, lo cual puede significar que las disputas que se dirimen en los juzgados se negocien más en términos de costumbres que ponen en desventaja a la mujer y no con relación a sus derechos.

Agencia de las mujeres indígenas y campo del derecho. Una dimensión más de la perspectiva de género que guía el trabajo de Victoria Chenaut es el constatar una alta incidencia de mujeres indígenas como usuarias del derecho que acuden a las instancias judiciales para negociar sus relaciones maritales y familiares, para denunciar violencia de género o para defender sus derechos (tierra). Una parte de asuntos que involucran delitos de en Coyutla, se convierten en causas penales; por ello el interés de Victoria de investigar como son tratados estos delitos en el ámbito municipal y que revelan sobre las relaciones de género. La tendencia principal de estos delitos penales son las disputas por los bienes, especialmente la tierra y los bienes. A través de la revisión de 48 averiguaciones previas que pasaron a instancias superiores y el seguimiento de 8 de ellas en el juzgado municipal, Victoria da cuenta del mapa de conflictos y de relaciones sociales involucradas, un termómetro de la vida social en la región. Algunos de estos asuntos involucraron largos procesos $\mathrm{y}$ distintos juicios y en ocasiones las fronteras entre agresor y agredido se difuminan. Los litigios revelan una importante agencia de las mujeres quienes disputan sus derechos vinculados con relaciones de propiedad en el contexto de dinámicas familiares. En estos procesos se pone en juego el poder de los papeles (títulos de propiedad), como si materializaran su posesión.

De esta manera Victoria Chenaut hace ver que los litigios judiciales se encuentran social y culturalmente situados, son productos de sociedades concretas y son el resultado de procesos interlegales donde se cruzan los distintos marcos normativos, del derecho estatal y el derecho indígena.

Derecho una de las vías que las mujeres usan para reclamar justicia. El seguimiento a casos que involucran a las mujeres permite analizar el campo del derecho como una arena para disputar normas, conceptos y definiciones de los roles de género. Las historias de vida de dos 
mujeres totonacas, analfabetas, $\mathrm{y}$ sin recursos económicos hace ver la agencia de las mujeres y su fuerza para dar seguimiento a procesos judiciales para defender su patrimonio y buscar justicia: es así que algunos de estos casos pasaron por diversas instancias y distintas fases del proceso judicial llegando incluso hasta el nivel federal ( pasando por las instancias municipales judiciales al Tribunal Superior de Justicia de Xalapa y en algunos casos hasta el Tribunal Federal del Distrito de Tuxpan. Se trata de historias representativas de mujeres decididas que acuden a la ley. En dichas historias cristalizan la interlegalidad, el peso de los órdenes de género, su negociación y los cambios en la vida de las mujeres. Victoria se pregunta si en este proceso desarrollan o no una consciencia jurídica para defender sus derechos.

3. ¿De qué justicia estamos hablando? Qué aporta el trabajo para la reflexión contemporánea sobre las justicias indígenas $\mathbf{y}$ sobre los nuevos modelos de la justicia penal acusatoria.

1) La variedad de casos analizados por Victoria revelan que acudir al derecho no necesariamente garantiza la justicia, debido

\footnotetext{
${ }^{2}$ Mauricio García Villegas (1993), La eficacia simbólica del derecho. Examen de situaciones colombianas. Bogotá, Ediciones Uniandes.
}

a lo largo y costoso de los procesos y al hecho que no necesariamente las decisiones judiciales se cumplen. Por lo mismo resulta relevante la pregunta recurrente sobre: porqué los indígenas totonacas acuden a la ley cuando no hay garantías que ésta se cumpla. Además del poder simbólico del derecho, el derecho es una arena de negociación que permite disputar poder desde ciertos marcos de posibilidad. Estas preguntas coinciden sin duda con interrogantes más generales sobre eficacia simbólica del derecho como bien lo ha enfatizado Mauricio García Villegas ${ }^{2}$

2). A diferencia de otros estados en México donde las reformas legales han impactado la justicia indígena abriendo espacios a su reconocimiento, en el caso de Veracruz, y muy especialmente en la Sierra de Papantla, esto no ha sucedido. Las transformaciones legales se han dado más en un sentido de reconocer la interculturalidad y el acceso a la justicia del estado como es el caso de los jueces itinerantes, pero no se ha dado el fortalecimiento de una justicia indígena.

3). El derecho estatal se ha debido flexibilizar y pluralizar para adecuarse de los cambios legales, sin dejar de imponer su hegemonía; pero sobre todo se ve que en las prácticas el derecho no sólo moldea y define 
las posibilidades de la acción legal sino que también es moldeado por los actores sociales a partir de sus propios contextos sociales y culturales. En una región donde están debilitadas las instancias de la justicia indígena, como es el caso de las comunidades de la Sierra de Papantla, se necesitan más espacios de mediación bajo modelos interculturales que permitan los diálogos y la participación de actores judiciales locales, incluidas las mujeres. Estos procesos deberían acompañarse de procesos organizativos localmente fortalecidos lo que sin embargo no parece suceder en el municipio de Coyutla, Veracruz. En estos contextos no es la profesionalización del campo jurídico la garantía de la justicia sino la construcción de espacios interculturales que respeten los estilos vernáculos de disputar . 